\title{
Determination of Small Amounts of Carbon Monoxide in Air by Various Reference Methods
}

\author{
By Martin Shepherd
}

\begin{abstract}
This is a report of the cooperative analyses of two samples of carbon monoxide in air. The analyses were made by laboratories engaged in investigations for the military services during the past war, and this work served to bring the results of these laboratories into common agreement.
\end{abstract}

\section{Object of the Investigation}

This work was undertaken to insure satisfactory accuracy of analytical results obtained by various laboratories using different fundamental reference methods for the determination of small amounts of carbon monoxide in air. As these reference methods are used to establish the composition of atmospheres in many researches dealing with the hazards, detection, and estimation of carbon monoxide, it is obviously necessary that essential agreement should exist between the different methods and the different laboratories engaged in such work. The cooperative analyses of identical samples has always been the most direct and successful way of measuring significant disagreement between different laboratories and different methods and of ultimately establishing satisfactory agreement. This approach was used in the present instance.

\section{Preparation of Samples}

The standard samples were prepared by the pressure-dilution method, which is well adapted to mixtures wherein one or more components are of relatively low partial pressure.

The apparatus used to prepare the standard samples was essentially a manifold with valves arranged so that connections between pressure gages, manometer, vacuum pump, and cylinders could be made in any desired combination. The valves were of the diaphragm-packless type or the
Stimson ${ }^{1}$ type and were vacuum-tight across seat, diaphragm, or (in the case of the Stimson valves) through the packing. The gages were of the laboratory-test type, carefully calibrated to the nearest $2 \mathrm{lb} / \mathrm{in}^{2}{ }^{2}$ and good to $4 \mathrm{lb} /$ in. $^{2}$ over the range 0 to $2,000 \mathrm{lb} / \mathrm{in}^{2}$ Two such gages were always connected for pressure readings. The mercuryfilled manometer was of the barometric type, of 20-mm bore, and was read with a cathotometer. The vacuum pump was of the regular commercial type capable of reducing the pressure to approximately $0.001 \mathrm{~mm}$ of mercury. Cylinders selected for this work were standard hydrogen steel cylinders (ICC 3A2015) and were equipped with diaphragm-packless valves that upon test were tight across the seat. The cylinders had previously been chained and brushed clean before inserting the valves and were dried by alternate evacuation and flushing with dried air.

It is obvious that some mixtures cannot be stored in steel cylinders; but mixtures of carbon monoxide in air, in the range of carbon monoxide desired for physiological work, do not change significantly over long periods when maintained under pressure. This fact has been carefully determined by periodically comparing samples of different ages. Comparisons were made over 2 years' duration with the NBS colorimetric method (laboratory procedure), capable of differentiating to 0.0002 percent by volume in the low concentrations studied. The samples submitted for the analyses reported herein were not stored longer

${ }_{1}^{1}$ Designed by Harold Stimson of the Bureau. 
than 4 months before the actual analyses were made.

The whole system, as connected for each specific procedure, was tested for leaks by evacuation and/or measurement of positive pressure over a definite period within the significance required. The apparatus was located within a laboratory where the variation in temperature does not exceed $1 \operatorname{deg} \mathrm{C}$ at any time.

The procedure for preparing a standard mixture of carbon monoxide in air (actually air with a small amount of additional nitrogen) was as follows. Carbon monoxide of known purity was transferred to a cylinder by alternate evacuation and flushing. The pressure of this carbon monoxide was adjusted to the existing measured barometric pressure. Compressed nitrogen was then admitted to the cylinder until the gage registered 99 existing atmospheres, after the heat of compression had been dissipated and the cylinder was in thermal equilibrium with the room. This resulting mixture, which was very close to 1 percent carbon monoxide, was diluted in the same manner, but with air, until its concentration had been reduced to 0.0100 percent, or to some desired value of this order.

The gases under pressure were thoroughly mixed by thermal convection. The cylinder was inclined to about 45 degrees, and the top was cooled while the bottom was heated for about 24 hours. Water from the cold and hot taps (about $15^{\circ}$ and $65^{\circ} \mathrm{C}$, respectively) served for this purpose.

The composition of the mixture with respect to carbon monoxide was computed from the equation

Percentage of $\mathrm{CO}=M_{\mathrm{CO}} \frac{P_{\mathrm{CO}}}{760} \frac{14.696}{P_{G}+14.7} \frac{R_{2}}{R_{1}} \frac{T_{2}}{T_{1}}$, in which

$M_{\mathrm{CO}}=$ percentage of carbon monoxide in the gas taken for dilution

$P_{\mathrm{CO}}=$ initial pressure of carbon monoxide or of a subsequent mixture of carbon monoxide with air, taken for dilution. (This is the existing barometric pressure in $\mathrm{mm} \mathrm{Hg}$, before dilution.)

$P_{G}=$ final gage pressure in $\mathrm{lb} / \mathrm{in}^{2}$

$R_{1}=$ value of $P V / n R T$ for carbon monoxide (or $N_{2}$ on the second dilution) at $1 \mathrm{~atm}$ and temperature $T_{1}$

$$
\begin{gathered}
\left.R_{2}=\text { value of } P V / n R T \text { for air (or } N_{2}\right) \text { at } \\
\text { the pressure } P_{G} \text { and temperature } \\
T_{2} \\
T_{1}=\text { initial cylinder temperature }\left(^{\circ} \mathrm{C}\right. \\
\text { abs. }) \\
T_{2}=\text { final cylinder temperature }\left(^{\circ} \mathrm{C}\right. \\
\text { abs. }) \text {. }
\end{gathered}
$$

The carbon monoxide used to prepare the two standard samples was analyzed by the apparatus and methods described by J. R. Branham, M. Shepherd, and S. Schuhmann [1]. ${ }^{2}$

The analysis was

$\begin{array}{lr}\mathrm{CO} \ldots & 97.94 \text { percent by volume. } \\ \mathrm{H}_{2 \ldots \ldots} \ldots & 2.03 \text { percent by volume. } \\ \mathrm{Fe}(\mathrm{CO})_{5 \ldots \ldots \ldots} \ldots .03 \text { percent by volume. }\end{array}$

The $\mathrm{Fe}(\mathrm{CO})_{5}$ was determined by condensing this substance from a measured large volume of sample, at approximately $-160^{\circ} \mathrm{C}$, in a condenser equipped with glass-wool filter, and determining the iron.

This reference method as described and corrected is good to less than 0.1 percent by volume of carbon monoxide. The pressures measured were good to $4 \mathrm{lb} /$ in. $^{2}$ (0.2 percent at maximum pressure). The temperatures were measured to 0.1 $\operatorname{deg} \mathrm{C}$. The maximum over-all uncertainty in preparing such mixtures at near the maximum operating pressures is about 0.0001 percent of carbon monoxide, and the probable uncertainty is less.

In the case of the two samples considered in this report, Sample 1 serves for a study of reproducibility and sample 2 for a study of both accuracy and reproducibility. When the samples were issued for analysis, it was thought that the composition of both was known to the desired significance, but review of the preparation of the first sample places too great an uncertainty upon its composition, and accordingly it will serve only as a means of showing the degree of reproducibility to be expected in the approximate range of 0.039 percent of carbon monoxide.

The standard samples were transferred to smaller cylinders for distribution to the various laboratories. This was done by connecting the large cylinder containing a standard sample and the small cylinders to a manifold. The whole system was evacuated and tested for tightness. Prior to the final filling under high pressure, the small

\footnotetext{
2 Figures in brackets indicate the literature references at the end of this paper.
} 


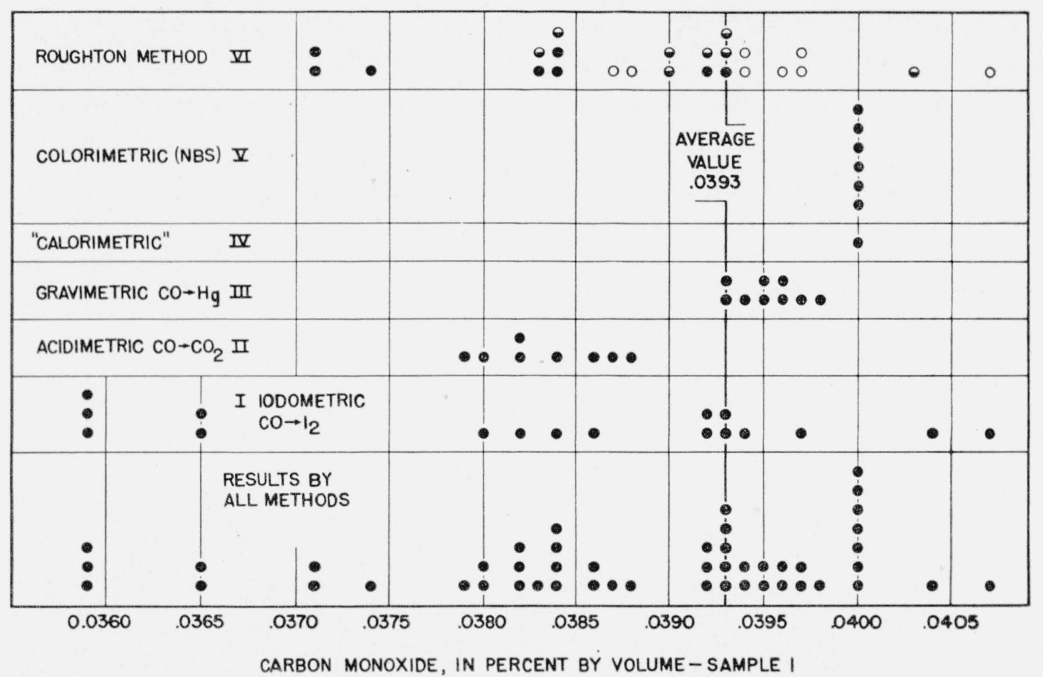

Figure 1.-Frequency-distribution plot for the analysis of a known sample of carbon monoxide in air.

cylinders were alternately evacuated and flushed with the standard sample.

The laboratories were thus assured of receiving identical samples.

\section{Analytical Results}

The two samples were submitted as unknowns, and no cooperating laboratory was given information concerning their composition other than the general statement that the mixtures were carbon monoxide in air. The results were reported directly to the Bureau and have been assembled for general study. Some really fine analytical work has been reported.

The analytical results are tabulated (table 1) and are also presented in two frequency-distribution plots, one for each sample (figs. 1 and 2). These plots show graphically the major facts to be derived from the analytical data. Each point or circle of the frequency-distribution plots represents the amount of carbon monoxide found by a single analysis, corrected by whatever factor

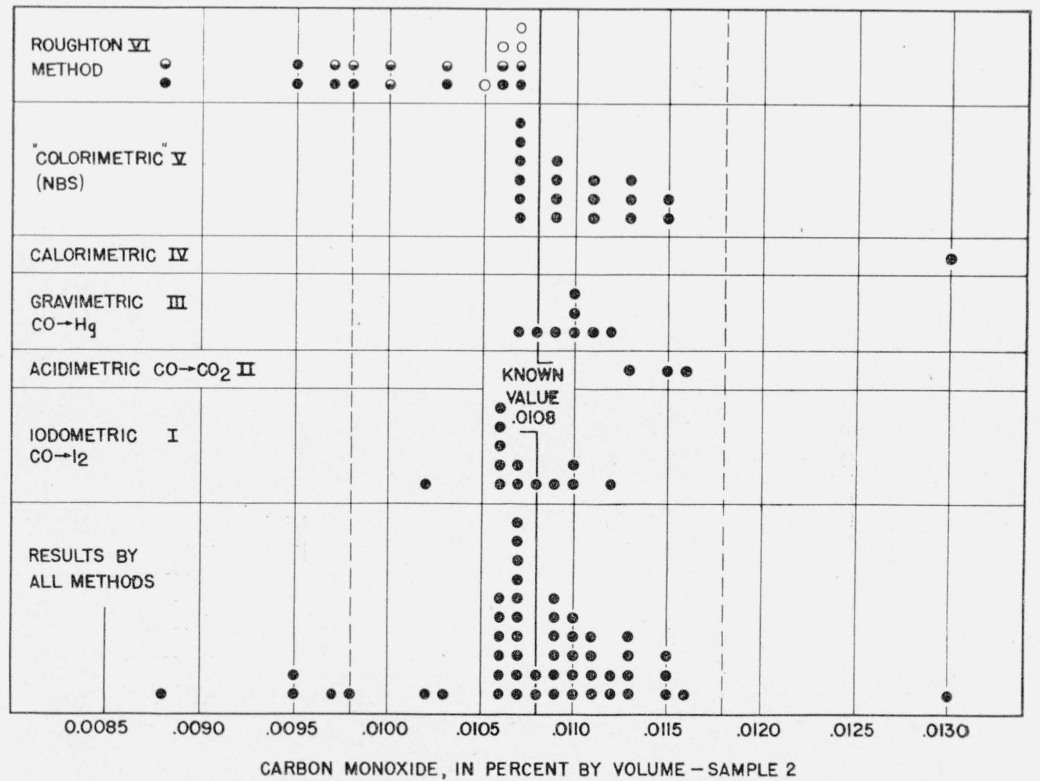

FIGURE 2.-Frequency-distribution plot for the analysis of a known sample of carbon monoxide in air. 
was furnished by the reporting laboratory. The circles are plotted equidistant on the ordinate corresponding to their value. Thus, the abscissas are percentages of carbon monoxide derived from the analyses, and the ordinates indicate the frequency with which these percentages occur. For example, the plot for sample 1 (fig. 1), bottom section (results by all methods) shows that seven separate analyses yielded the value 0.0400 percent, one analysis gave the value 0.0398 percent, two analyses gave the value 0.0397 percent, and so on.

TABLE 1.-Cooperative analysis of two Standard Samples of carbon monoxide in air, by reference methods used in various laboratories working for the Armed Forces

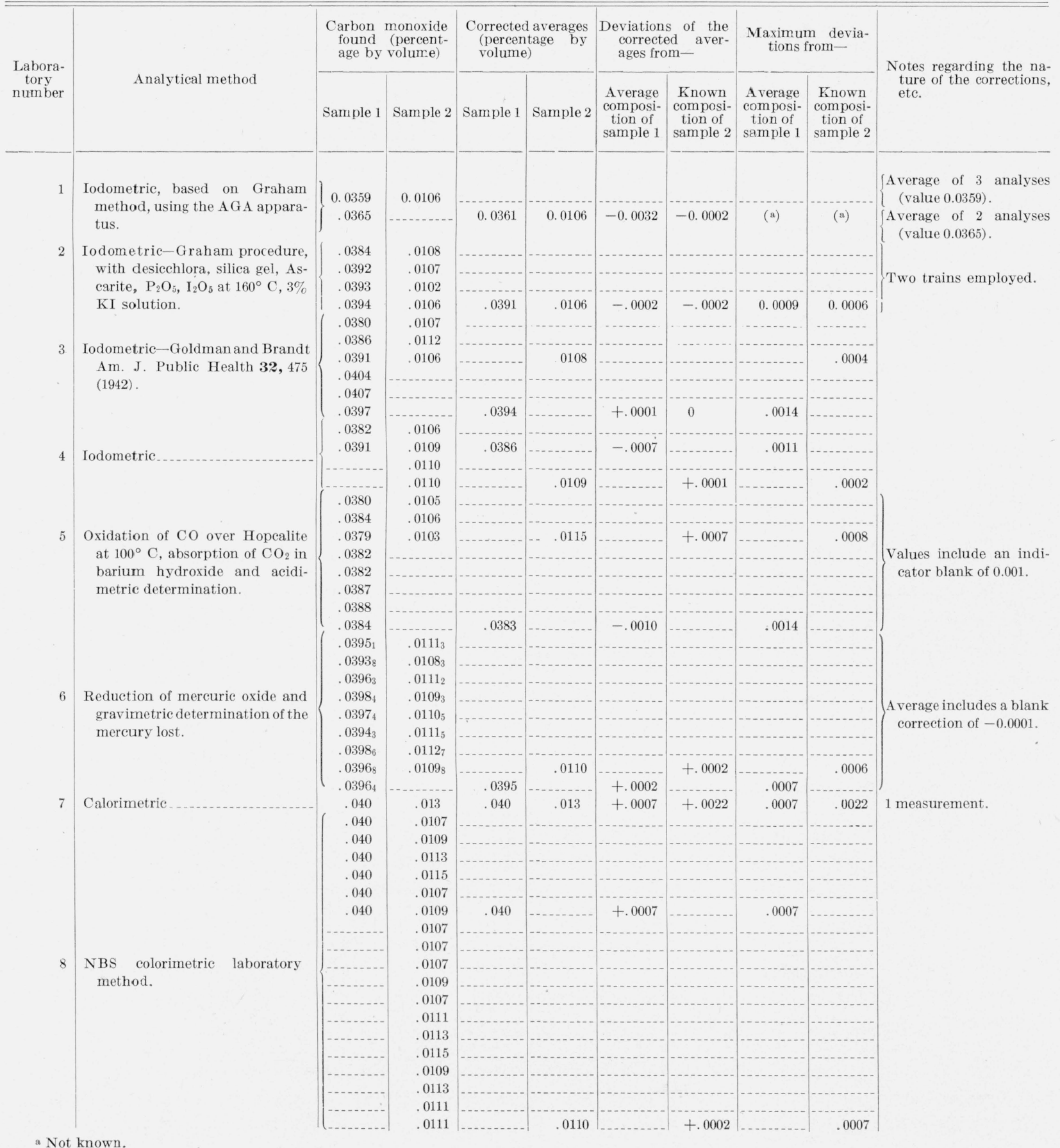


TABLE 1.-Cooperative analysis of two Standard Samples of carbon monoxide in air, by reference methods used in various laboratories working for the Armed Forces - Continued

\begin{tabular}{|c|c|c|c|c|c|c|c|c|c|c|}
\hline \multirow{2}{*}{$\begin{array}{l}\text { Labora- } \\
\text { tory } \\
\text { number }\end{array}$} & \multirow{2}{*}{ Analytical method } & \multicolumn{2}{|c|}{$\begin{array}{l}\text { Carbon monoxide } \\
\text { found (percent- } \\
\text { age by volume) }\end{array}$} & \multicolumn{2}{|c|}{$\begin{array}{l}\text { Corrected averages } \\
\text { (percentage by } \\
\text { volume) }\end{array}$} & \multicolumn{2}{|c|}{$\begin{array}{l}\text { Deviations of the } \\
\text { corrected aver- } \\
\text { ages from- }\end{array}$} & \multicolumn{2}{|c|}{$\begin{array}{l}\text { Maximum devia- } \\
\text { tions from- }\end{array}$} & \multirow{2}{*}{$\begin{array}{l}\text { Notes regarding the na- } \\
\text { ture of the corrections, } \\
\text { etc. }\end{array}$} \\
\hline & & Sample 1 & Sample 2 & Sample 1 & Sample 2 & $\begin{array}{c}\text { A verage } \\
\text { composi- } \\
\text { tion of } \\
\text { sample } 1\end{array}$ & $\begin{array}{l}\text { Known } \\
\text { composi- } \\
\text { tion of } \\
\text { sample } 2\end{array}$ & $\begin{array}{c}\text { Average } \\
\text { composi- } \\
\text { tion of } \\
\text { sample } 1\end{array}$ & $\begin{array}{l}\text { Known } \\
\text { composi- } \\
\text { tion of } \\
\text { sample } 2\end{array}$ & \\
\hline 10 & $\begin{array}{l}\text { Roughton method, which includes } \\
\text { absorption of CO in blood, sub- } \\
\text { sequent removal therefrom by } \\
\text { Van slyke procedures, and final } \\
\text { determination by absorption in } \\
\text { ammoniacal cuprous chloride in a } \\
\text { Scholander-Roughton micropi- } \\
\text { pette. Four sets of results were } \\
\text { submitted. (See remarks.) }\end{array}$ & $\begin{array}{r}0.0377 \\
.0384 \\
.0371 \\
.0374 \\
.0371 \\
.0383 \\
.0393 \\
.0392 \\
.0384 \\
.0403 \\
.0390 \\
.0393 \\
.0390 \\
.0383 \\
.0393 \\
.0392 \\
.0384 \\
.0407 \\
.0394 \\
.0397 \\
.0394 \\
.0387 \\
.0397 \\
.0396 \\
.0388 \\
. \ldots . \\
. .-1 \\
. .-\end{array}$ & $\begin{array}{r}0.0098 \\
.0106 \\
.0103 \\
.0098 \\
.0088 \\
.0095 \\
.0097 \\
.0095 \\
.0107 \\
.0106 \\
.0103 \\
.0098 \\
.0088 \\
.0100 \\
.0097 \\
.0100 \\
.0107 \\
.0106 \\
.0103 \\
.0098 \\
.0088 \\
.0100 \\
.0097 \\
.0100 \\
.0107 \\
.0105 \\
.0106 \\
.0107 \\
.0107 \\
\end{array}$ & .0393 & .0099 & -.0011 & -.0009 & $\begin{array}{l}\text { (a) } \\
0.0022\end{array}$ & $\begin{array}{c}\text { (a) } \\
0.0020 \\
0020 \\
0 \\
0 \\
\end{array}$ & $\begin{array}{l}\text { First values corrected for } \\
\text { an error found in one } \\
\text { apparatus. } \\
\text { Corrected values cor- } \\
\text { rected for excess of ni- } \\
\text { trogen in the sample } \\
\text { over the amount in air. } \\
\text { Results from the im- } \\
\text { proved method, which } \\
\text { consists in using a } 300- \\
\text { ml sample instead of a } \\
30 \text {-ml sample. }\end{array}$ \\
\hline
\end{tabular}

a Not known.

\section{Sample 1}

Practically the whole story of sample 1 can be seen in figure 1 . The bottom section gives a picture of the distribution of analytical results by all the methods employed. Most of the results are clustered between the values 0.0380 and 0.0400 , with the greatest frequency near and at the higher value. If the five low results by the iodometric method are eliminated, the arithmetical average of all other results is 0.0392 ; and with the highest and the lowest 10 percent of all values dropped, the average is 0.0393 . This value is taken as the average result of the analyses of sample 1 .

These data are in turn broken down to obtain the picture of each of the analytical methods used. The second section from the bottom of this plot gives this picture for the iodometric method (I), generally called the iodine pentoxide method [2]. Referring now to the table, it is noted from columns 1 and 2 that four laboratories used this method, with some variations, and that the five low results reported are from one of the four laboratories. The values for this method are relatively scattered and suggest the need for standardizing the actual procedures used. The average of all results by this method is 0.0383 , lower than the average value by all methods; the average of all results after dropping the five low ones is 0.0392 , in good agreement with the average value by all methods.

The next section of the plot gives the results reported by an acidimetric method (II) [3]. According to this method, carbon monoxide is converted to carbon dioxide by Hopcalite at $100^{\circ} \mathrm{C}$, and the carbon dioxide is absorbed in barium hydroxide and determined acidimetrically. The 
results plotted are corrected for an indicator blank of 0.001 . These results are well grouped and all are lower than the average value by all methods. The average is 0.0383 .

The next section gives the results [4] from a gravimetric method (III) that depends upon the reduction of mercuric oxide at $175^{\circ} \mathrm{C}$. Carbon monoxide is calculated from the measured loss of weight of the oxide. These results are very well clustered near the general average value, with an average of 0.0395 , and leave little to be desired, even by the most exacting analysts.

The next section gives one point reported by a "calorimetric method" (IV), wherein the rise of temperature produced by the combustion on Hopclalite at $100^{\circ} \mathrm{C}$ is measured by a mercuryin-glass thermometer.

Section $\mathrm{V}$ gives values obtained by the NBS colorimetric method [5]. When CO occurs in amounts as large as 0.03 to 0.04 percent, it is estimated to the nearest 0.001 percent by this method. The apparent excellent reproducibility should accordingly not be misunderstood because the choice here was merely between $0.039,0.040$, or 0.041 percent, and the observations indicated an even 0.040 percent.

The Roughton method outlined in section VI employs the following procedures. The sample is freed from oxygen, and thereafter the carbon monoxide is absorbed by prolonged contact with blood. The blood is then freed from other gases by Van Slyke procedures in the Van Slyke manometric apparatus, and after removal of these gases, the carbon monoxide is liberated, and the final residue of carbon monoxide is transferred to a Scholander-Roughton microsyringe and there absorbed in ammoniacal cuprous chloride.

The original results obtained by this method are those indicated by the filled circles. One laboratory reported an average of 0.0377 percent, and another reported an average of 0.0382 percent. The results are badly scattered. Later the second laboratory reported an average of 0.0391 , based on corrections made for an error found. These results are indicated by the half-filled circles. Still later, these results were in turn corrected because of the fact that the measurement of the sample was based upon the determination of nitrogen in the sample and the assumption that the sample was air and carbon monoxide, whereas slightly more nitrogen was actually in the sample than corresponded to the composition of air. The third set of values averaged 0.0393 (excluding the highest value) and are indicated by the open circles. The results are still somewhat scattered, though the average has finally reached the probable value, which attests to the astonishingly skillful manipulation that must have been accorded each step of this devious procedure.

\section{Sample 2}

Sample 2 seems to have been the inspiration for some really fine analytical work. The frequencydistribution plot for this sample appears in figure 2. Dotted boundaries have been drawn 0.001 percent away from the known value of 0.0108 . The bottom section of the plot gives results obtained by all methods, and it is at once apparent that all but five of these values fall within the \pm 0.001 boundaries. Indeed, most of the analyses by the five entirely different methods lie within \pm 0.0005 percent of the known value, which is more than could have been hoped for.

The picture for each of the methods is given in the upper sections of this frequency-distribution plot. The values obtained by the "iodine pentoxide" method (I) do not show the wide distribution noted in the plot for sample 1 . The one slightly low value was not reported from the same laboratory which gave the notably low values for sample 1. The need for standardization of this method is not so apparent in this instance. The average of all values is 0.0107 , in excellent agreement with the known value 0.0108 .

Acidimetric values (II) are well grouped and are all high instead of low this time. All are within the \pm 0.001 boundary. The average is 0.0115 .

Gravimetric values (III) are consistently grouped and all are within 0.0004 of the known value. The average, $0.0110\left(0.0109_{6}\right)$, is slightly high. This method seems to have given the most consistent over-all performance with the low and high range of composition. The error for each sample was small, and apparently systematic. Thus, a redetermination of the blank or possibly a check of the measurement of the volume of the sample might establish an average in even closer agreement with the known value, if there is any desire to do so.

A single high point is noted for the calorimetric method (IV). 
The colorimetric method (V) yielded values fairly well grouped, all within the \pm 0.001 boundaries, and mostly within the \pm 0.0005 boundaries. The fact that all values noted are odd numbers follows merely because the standard colors prepared for comparison with the unknown represented numerically even percentages, and the unknowns are, of course, placed between the standards when the color readings are made.

As before, several sets of values were reported from the second laboratory employing the physiological method, each set in succession approaching the known value more closely. The first set (closed circles) yielded an average of 0.0099 percent. (The first of the laboratories using this method reported 0.0098 percent.) The second set, corrected for a discovered error, gave an average of 0.0100 (half-closed circles). The third set, corrected for the nitrogen ratio before mentioned, did not change by a significant amount. There is also a fourth set, obtained with a $300-\mathrm{cm}^{3}$ sample instead of a $30-\mathrm{cm}^{3}$ sample. These determinations (open circles) yielded an average of 0.0107 .

Further brief study may be devoted to the details given in the tabulated data. The data given in columns 5 and 6 are worth a moment's additional reflection. With the exception that is obviously out of line with the other data, the greatest deviation of an average value from the known value for sample 2 is 0.0009 , and this includes all methods. This means that if the analyst is not inclined to take a chance with a single determination, but instead has a sufficiently healthy curiosity to perform a series of analyses, his chance of getting very close to the correct answer with any of these methods is good. If he is not too concerned with accuracy, a single determination might leave him in error by amounts varying from 0.0002 up to 0.002 percent (dropping: the outside value obtained by method IV), with a good chance of his being off by no greater than 0.0008 in this range of composition.

\section{Practical Considerations}

Factors like ease of manipulation, time required, complexity, cost and difficulty of maintaining apparatus, complications that may be involved in removing interfering substances, range of applicability, and such matters for practical consideration have so far not been discussed. The selection of a reference method for a particular purpose should include an appraisal from this angle, but as such matters often involve personal judgment to an embarrassing degree, no formal rating of these characteristics will be ventured. However, an informal review is in order. The following are general considerations.

1. All of the methods demand the use of known mixtures of carbon monoxide in air for calibration and regular check of performance. The colorimetric method requires the continual use of known mixtures.

2. All of the methods must make provision for interfering substances, although curiously enough, the interference in the Roughton method occurs within the analytical procedures rather than as the usual prelude to them. This comes about because blood is specific with respect to absorption of the carbon monoxide from the sample; but after this initial step, the carbon monoxide must be separated from the interfering gases in solution in the blood. Contrasted to this, the other methods are susceptible to interfering gases, such as unsaturated compounds and heavy organic vapors, that must be removed as the initial step. This is true even for the acidimetric method, for, while the catalyst used to oxidize carbon monoxide is specific for this gas, nevertheless, it is susceptible to poisoning. The removal of interfering substances is more simply accomplished with the colorimetric and gravimetric methods. (A possible exception may be the removal of hydrogen in the gravimetric method. Hydrogen does not interfere in the colorimetric method.)

3. The iodometric method requires the most complicated and costly apparatus and the one which is most troublesome to maintain in good operating order. The colorimetric method uses the simplest and cheapest apparatus and the one most easily maintained in running order.

4. The colorimetric method is not as accurate for larger amounts of carbon monoxide, unless the original sample is diluted with CO-free air. The dilution procedure will make its range comparable to that of the other methods.

5. The colorimetric method is by far the most rapid, and is by far the easiest to perform. This assumes, however, that known mixtures are available under pressure. The time spent in preparing such mixtures is not a serious factor when considering the exceedingly long life of the mixture. However, the apparatus required to prepare such 
mixtures, although not expensive, must be assembled with a great deal of care, and is almost useless for any other purpose. "It would accordingly be desirable to establish a suitable common source of such mixtures.

\section{References}

[1] Joseph R. Branham, Martin Shepherd, and Shuford Schuhmann, Critical study of the determination of carbon monoxide by combustion over platinum in the presence of excess oxygen, J. Research NBS $\mathbf{2 6}$, 571 (1941) RP1396.
[2] J. Ivor Graham, The accurate determination of carbon monoxide in gas mixtures, Soc. Chem. Ind. 38 10-4T (1919).

[3] Cobb Chemical Laboratory, University of Virginia, University, Va. (Unpublished report).

[4] Arnold Beckman, National Technical Laboratory, S. Pasadena, Calif. (Unpublished report.)

[5] Martin Shepherd, A preliminary report on the NBS colorimetric indicating gel for the rapid determination of small amounts of carbon monoxide, Anal. Chem. 19, 77 (Feb. 1947).

Washington, November 1, 1946. 